\title{
Reviewing for an OJS Journal
}

See the video here: $\underline{\text { https://www.youtube.com/watch?v=KUnmiae19A0 }}$ 